\title{
Repeat hepatic resections for colorectal metastases
}

\author{
Kean D. Griffith, MD, Paul H. Sugarbaker, MD, and Alfred E. Chang, MD, \\ Bethesda, Md., Atlanta, Ga., and Ann Arbor, Mich.
}

\begin{abstract}
We identified 106 patients who had undergone complete resection of isolated colorectal hepatic metastases. Nine of these patients subsequently underwent repeat liver resections for isolated hepatic recurrences. The median follow-up for these patients was 21 months. One postoperative death was related to the second hepatectomy. At the time of last follow-up, five patients were alive and free of recurrent disease at 9, 19, 31, 50, and 67 months after their second hepatic resection. The remaining three patients were alive, but disease had recurred 11 months after resection in the first patient, 12 months after resection in the second, and 18 months after resection in the third. Among these three patients, two had solitary pulmonary nodules, which were resected, and one had unresectable liver disease. Our experience and a review of the literature suggest that repeat hepatic resection for isolated colorectal metastases can result in long-term survival in selected patients. (SURGERY 1990;107:101-4.)
\end{abstract}

From the Surgery Branch, National Cancer Institute, Bethesda, Md., Winship Cancer Center, Emory University School of Medicine, Atlanta, Ga., and the Division of Surgical Oncology, University of Michigan, Ann Arbor, Mich.

OVER THE PAST 20 years, many reports have documented that surgical resection of isolated hepatic metastases from colorectal carcinoma can result in a $25 \%$ to $30 \% 5$-year survival benefit. ${ }^{1-13}$ Relative contraindications for hepatic resection include the presence of positive hepatic nodes, extrahepatic metastases, or four or more liver metastases. ${ }^{12}$ As this therapy has gained acceptance, the question of appropriate therapy for recurrent hepatic metastases has become relevant. We present our experience with hepatic resection along with an overview of the few anecdotal case reports to be found in the literature.

\section{RESULTS}

Between 1970 and 1987, 106 patients had undergone resection of colorectal liver metastases at the National Cancer Institute (84 patients) or Emory University School of Medicine (22 patients). Among these patients, $9 \mathrm{had}$ a second hepatic resection of recurrent liver metastases (7 at NCI, 2 at Emory). Median follow-up for

Accepted for publication March 31, 1989

Reprint requests: Alfred E. Chang, MD, Division of Surgical Oncology, University of Michigan Medical Center, Box 0331, 1500 E. Medical Center Dr., Ann Arbor, MI 48109 .

$11 / 56 / 14278$ these patients was 21 months (range, 9 to 67) from the time of the second liver resection.

A summary of these nine cases is compiled in Table I. The median patient age at follow-up was 57 years (range, 44 to 70 years). There were six men and three women. At the first hepatic resection, eight patients had wedge resections and one patient had a right trisegmentectomy for removal of metastatic lesions. Wedge resections were classified as operations that entailed the removal of less than a major lobe. Seven patients had solitary metastases, while patients 3 and 5 had bilobar metastases. Patients 3 through 9 had documented negative resection margins; the status of resection margins for patients 1 and 2 is unknown. In six of nine patients, hepatic resections were performed at the time of primary tumor excisions. The remaining three patients had resection of metachronous liver tumors, which were all diagnosed by elevations in carcinoembryonic antigen levels. Patient 2 received adjuvant systemic fluorouracil chemotherapy after the first hepatic resection.

The median interval from the time of the first hepatic resection to the diagnosis of the hepatic recurrence was 21 months (range, 1 to 39 months). Recurrent disease was initially diagnosed on the basis of elevations in carcinoembryonic antigen levels in six patients and computed tomography (CT) scans in the other three patients. Preoperative evaluation to exclude extrahe- 
Table I. Summary of patients who had second hepatic resections for colorectal metastases

\begin{tabular}{|c|c|c|c|c|c|c|c|c|c|c|}
\hline \multirow[b]{2}{*}{ Patient } & \multirow[b]{2}{*}{ Age Sex } & \multirow[b]{2}{*}{$\begin{array}{l}\text { Primary tumor } \\
\text { Location/Stage }\end{array}$} & \multicolumn{3}{|c|}{ First hepatic resectiont } & \multicolumn{4}{|c|}{ Second hepatic resectionf } & \multirow[b]{2}{*}{ Follow-up§ } \\
\hline & & & $\begin{array}{l}D F I \\
(m o)\end{array}$ & Nodules & Operation & $\begin{array}{l}D F I \\
(m o)\end{array}$ & Nodules & Operation & Adj. & \\
\hline 1 & $56 \mathrm{M}$ & Sigmoid/B2 & 18 & 1 & $\mathrm{R}$ wedge & 3 & 5 & R lobectomy & $+\|$ & $\mathrm{NED}, 67 \mathrm{mo}$ \\
\hline 2 & $63 \mathrm{M}$ & Sigmoid/C2 & 0 & 1 & $R$ wedge & 33 & 4 & R lobectomy & + & NED, 50 mo \\
\hline 3 & $57 \mathrm{M}$ & Rectal/C2 & 0 & 3 & $\begin{array}{l}\mathrm{R} \text { wedge (2) } \\
\mathrm{L} \text { wedge (1) }\end{array}$ & 37 & 1 & L lobectomy & + & $\mathrm{NED}, 25 \mathrm{mo} \mathbb{I}$ \\
\hline 4 & $67 \mathrm{~F}$ & $\mathrm{R}$ colon $/ \mathrm{B} 2$ & 0 & 1 & L wedge & 25 & 1 & $\begin{array}{l}\text { R trisegmen- } \\
\text { tectomy }\end{array}$ & + & $\begin{array}{l}\text { Died, } 4 \text { th } \\
\text { postop day }\end{array}$ \\
\hline 5 & $62 \mathrm{~F}$ & Sigmoid/B2 & 0 & 2 & $\mathrm{R}+\mathrm{L}$ wedge & 39 & 1 & R lobectomy & + & $\mathrm{NED}, 31 \mathrm{mo}$ \\
\hline 6 & $70 \mathrm{M}$ & Rectal/C2 & 0 & 1 & L wedge & 19 & 1 & $\mathrm{R}$ wedge & + & $\mathrm{AWD}, 16 \mathrm{mo}$ \\
\hline 7 & $44 \mathrm{M}$ & Rectal/C2 & 0 & 1 & $\mathrm{R}$ wedge & 1 & 1 & R lobectomy & - & $\mathrm{NED}, 21 \mathrm{mo} \mathbb{I}$ \\
\hline 8 & $59 \mathrm{M}$ & $\begin{array}{l}\text { Sigmoid/C2 } \\
\text { Rectum/C2\# }\end{array}$ & 18 & 1 & L wedge & 8 & 1 & $\mathbf{R}$ wedge & - & $\mathrm{NED}, 9 \mathrm{mo}$ \\
\hline 9 & $53 \mathrm{~F}$ & Sigmoid/B2 & 34 & 1 & $\begin{array}{l}\mathrm{R} \text { trisegmen- } \\
\text { tectomy }\end{array}$ & 21 & 1 & L wedge & - & NED, 19 mo \\
\hline
\end{tabular}

* Site and locoregional stage of primary tumor (Astler and Coller classification system).

tData for first hepatic resection include disease-free interval (DFI), documented in months from time of resection of primary tumor to diagnosis of hepatic metastasis (synchronous $=0$ ), and number of nodules resected and type of operation.

$\ddagger$ Data for second hepatic resection include disease-free interval (DFI), documented in months from time of lirst hepatic resection to diagnosis of second hepatic metastasis, number of nodules resected, type of operation, and adjuvant therapy $(\Lambda \mathrm{dj})$ after second hepatic resection.

$\S$ Follow-up status in months from second hepatic resection. NED, no evidence of disease; AWD, alive with disease.

||Plus sign (+) represents administration of adjuvant intraperitoneal fluorouracil therapy.

IResection of solitary pulmonary metastasis 11 and 18 months from second hepatic resection in patients 3 and 7 , respectively

\#Sigmoid lesion was initially resected and patient was found to have a metachronous rectal tumor.

patic metastases included barium studies of the large bowel, CT scans of the chest and abdomen, and a bone scan. Intraoperative abdominal exploration involved careful palpation and biopsies of hepatic lymph nodes that were found to be clincally suspicious. Seven patients had solitary nodules, while each of the remaining patients had four or five tumor nodules. Second hepatic resections included five lobectomies, one trisegmentectomy, and three wedge resections. Hepatic resection margins for these procedures were all documented to be negative. The one postoperative death involved patient 4 , who died of a myocardial infarction occurring on the fourth postoperative day. Five patients were alive and free of disease at 9, 19,31, 50, and 67 months after the second liver resection. Six patients were given adjuvant intraperitoneal fluorouracil therapy via a Tenckhoff catheter, as previously described. ${ }^{4}$ The median survival for all patients was 21 months.

At the end of the follow-up period, three patients had experienced recurrence of disease. Patients 3 and 7 developed solitary pulmonary nodules 11 and 18 months, respectively, after the second hepatic resection. These patients underwent pulmonary metastasectomies and were still alive without recurrent disease 14 and 3 months, respectively, after these procedures. Patient 6 had unresectable disease of the liver 12 months after the second hepatectomy and remained alive with disease at the time of his last follow-up.

\section{DISCUSSION}

It is estimated that approximately $10 \%$ of all patients with hepatic metastases from colorectal cancer may benefit from liver resection since their recurrent disease is confined to the liver. ${ }^{14}$ The Registry of Hepatic Metastases reported a collected series of 859 patients who had undergone resection of colorectal liver metastases. These patients, it was discovered, had a 5-year survival rate of $33 \% .^{12}$ In a follow-up study reported by the Registry, the site of recurrence in those patients who had complete resection of liver metastases was examined. ${ }^{15}$ The liver was the most common site, with $28 \%$ of the patients having recurrences limited to the liver and $11 \%$ having recurrences in the liver plus other sites. Among our series of nine patients undergoing second hepatic resections, seven patients were documented to have negative pathologic margins at the time of the first hepatectomy, while in the remaining two patients the status of the surgical margins were undetermined. Therefore, it is unlikely that the subsequent recurrences of disease in the liver were related to inadequate first hepatic resections. More likely, the later hepatic recurrences were due to occult liver tumors that were not 
Table II. Summary of reported cases of second hepatic resection for colorectal cancer

\begin{tabular}{|c|c|c|c|c|}
\hline Author & No. patients & First procedure & Second procedure & Follow-up* \\
\hline \multirow[t]{6}{*}{ Nordlinger et al. ${ }^{11}$} & 6 & Wedge resection & $\mathrm{R}$ trisegmentectomy & Dead at $25 \mathrm{mo}$ \\
\hline & & Wedge resection & $\mathrm{R}$ trisegmentectomy & AWD at $23 \mathrm{mo}$ \\
\hline & & Wedge resection & $\mathrm{R}$ trisegmentectomy & NED at $17 \mathrm{mo}$ \\
\hline & & Wedge resection & $\mathrm{R}$ lobectomy & $\mathrm{NED}$ at $42 \mathrm{mo}$ \\
\hline & & Wedge resection & $\mathrm{R}$ lobectomy & AWD at $41 \mathrm{mo}$ \\
\hline & & Wedge resection & Wedge resection & $\mathrm{NED}$ at $40 \mathrm{mo}$ \\
\hline \multirow[t]{2}{*}{ Butler et al. ${ }^{6}$} & 2 & Wedge resection & Lobectomy & NED at $6 \mathrm{mo}$ \\
\hline & & Wedge resection & Lobectomy & $\mathrm{NED}$ at $17 \mathrm{mo}$ \\
\hline Tomas-de la Vega et al. ${ }^{9}$ & 4 & Not reported & Not reported & $\begin{array}{l}\text { AWD (2), NED (2); } \\
\text { mean survival rate }=22 \mathrm{mo}\end{array}$ \\
\hline \multirow[t]{3}{*}{ Fortner 20} & 3 & Lobectomy & Wedge resection & AWD at 39 mot \\
\hline & & Lobectomy & Wedge resection & Alive at $5+$ mo $\ddagger$ \\
\hline & & Lobectomy & Wedge resection & Dead at $16 \mathrm{mo}$ \\
\hline
\end{tabular}

* Follow-up status in months from sccond hepatic resection. NED, No evidence of disease: $\triangle W D$, alive wish disease.

+Recurrent disease in lung and pelvis documented 7 months after second liver resection. Had four subsequent operations for localized recurrent disease.

$\ddagger$ Had a second recurrence of the disease in the liver and underwent third liver resection. Alive 5 months after last liver resection

detected at the time of the first hepatic resections. The increasing use of intraoperative ultrasound may improve the ability of the surgeon to detect occult lesions not identified by CT scanning or manual palpation at the time of surgery, and it may also aid in achieving adequate surgical margins. ${ }^{16}$

Data from the literature and our experience suggest that approximately one third of all isolated liver metastases are technically resectable. In the past, the major deterrent to aggressive metastasectomies of the liver has been the associated morbidity and mortality. Increased blood loss and transfusion requirements have been reported to increase postoperative complications and decrease disease-free and overall survival after liver resections. ${ }^{4,17}$ Advances in hepatic parenchymal dissection and diagnostic evaluation of colorectal cancer also offer promise for improving the feasibility of hepatic metastasectomies. The Cavitron ultrasonic surgical aspirator (CUSA) has been reported to provide a more controlled dissection of the hepatic parenchyma with better identification of vasculobiliary structures and decrease operative blood loss, compared with conventional techniques. ${ }^{18}$ Careful monitoring of carcinoembryonic antigens can lead to the earlier detection of recurrent liver tumor that may be more amenable to surgical resection. ${ }^{19}$ Likewise, newer diagnostic scanning techniques have improved the sensitivity and resolution of diagnosing smaller hepatic nodules.

Our study encompasses the largest reported series of patients who have undergone second liver resections for colorectal metastases. Four other reports have commented on a total of 15 patients who have had repeat liver resections for metastases. ${ }^{6,9,11,20}$ A summary of these other cases is listed in Table II. Seven of these 15 patients remained alive and free of disease at the time of follow-up 6 to 42 months after their second hepatic resection. Among the nine patients reviewed in our series, two have remained free of disease for more than 4 years, longer than any patient in the previous reports. Combining the data on all the patients with individual follow-up information from our series and others, we concluded that the median survival time for patients after their second liver resection was 22 months $(n=20)$.

The events leading to the growth and development of metastatic disease in lymph nodes or visceral organs are complex and poorly understood. ${ }^{21}$ Surgical resection of metastatic disease has been a therapeutic option that has been traditionally dismissed by clinicians as being curative. However, it should be reiterated that surgical resection of regional lymphatic metastases from solid tumors such as melanoma and colorectal and breast carcinomas can be curative in $25 \%$ to $40 \%$ of patients. ${ }^{22}$ For blood-borne visceral metastases, extensive clinical experience has documented that resection of isolated pulmonary and hepatic tumors can result in $25 \%$ to $30 \%$ long-term survival. ${ }^{1-13,23}$ The ability to cure a select group of patients with metastatic disease involving the lymph nodes or visceral organs by surgical means alone suggests that the number of residual micrometastatic tumor cells can be reduced to a level capable of being destroyed or suppressed by host mechanisms.

The therapeutic benefits of reoperation for recurrent metastases in the lung have been documented. Rizzoni et al. ${ }^{24}$ reported on the National Cancer Institute (NCI) experience of repeat pulmonary resections for soft-tissue sarcoma lung metastases which resulted in prolonged 
survival. ${ }^{24}$ Twenty-nine patients who had two or more pulmonary resections had a median survival of 14.5 months, with a 3 -year survival of $22 \%$. No major operative morbidity was associated with repeat pulmonary resections. The biologic principles that allowed for prolonged survival after reoperation for recurrent metastases in the lung may also be valid in the case of repeat hepatic resections of colorectal metastases. The technical problems of performing repeat pulmonary resections (up to four in the NCI experience) are clearly less than for repeat hepatic resections. However, the unique ability of the liver to regenerate may make a second liver resection more feasible. For example, patient 9 underwent an initial right trisegmentectomy for a $4 \mathrm{~cm}$ metastasis within the medial segments of the right and left lobes; 21 months later, the patient was able to undergo a large wedge resection of a $5 \mathrm{~cm}$ solitary metastasis in the residual left lobe, which had exhibited marked regeneration.

In our series, six patients received adjuvant intraperitoneal fluorouracil after the second hepatic resection (Table I); however, the role of adjuvant chemotherapy in patients surgically rendered free of metastatic disease in the liver has yet to be established. Effective adjuvant treatment after liver metastasectomies is an important area for future investigation. The cases presented here, as well as a review of the literature, suggest that aggressive repeat resection of recurrent colorectal metastases confined to the liver may be beneficial in selected patients.

\section{REFERENCES}

1. Fortner JG, Silva JS, Golbey RB, Cox EB, MacLean BJ. Multi-variate analysis of a personal series of 247 consecutive patients with liver metastases from colorectal cancer. Ann Surg 1984;199:306-16

2. Petrelli NJ, Nambisan RN, Herrera L, Mittelman A. Hepatic resection for isolated metastases from colorectal carcinoma. Am J Surg 1985;149:205-9.

3. Adson MA, van Heerden JA, Adson MH, Wagner, JS, Istrup DM. Resection of hepatic metastases from colorectal cancer. Arch Surg 1984;119:647.

4. August DA, Sugarbaker PH, Ottow RT, Gianola FJ, Schneider PD. Hepatic resection of colorectal metastases: influence of clinical factors and adjuvant intraperitoneal 5-FU via Tenckhoff catheter. Ann Surg 1985;201:210-8.

5. Cady B, McDermott WV. Major hepatic resection for metachronous metastases from colon cancer. Ann Surg 1985;201:204-9.

6. Butler J, Attiyeh FF, Daly JM. Hepatic resection for metastases of the colon and rectum. Surg Gynecol Obstet 1986;162:109-13.
7. Gennari L, Doci R, Bignami P, Bozzetti F. Surgical treatment of hepatic metastases from colorectal cancer. Ann Surg 1986; 203:49-54.

8. Coppa GF, Eng K, Ranson JHC, Gonge TH, Localio, SA. Hepatic resection for metastatic colon and rectal cancer: an evaluation of preoperative and postoperative factors. Ann Surg 1985;202:203-8.

9. Tomas-de la Vega JE, Donahue EJ, Doolas A, et al. A ten year experience with hepatic resection. Surg Gynecol Obstet 1984; 159:223-8.

10. Iwatsuki S, Shaw BW, Starzl TE. Experience with 150 liver resections. Ann Surg 1983;197:247-53.

11. Nordlinger B, Parc R, Delva E, Quilichini MA, Hannoun L, Huguet, C. Hepatic resection for colorectal liver metastases. Ann Surg 1987;205:256-63.

12. Hughes KS, Simon R, Songhorabodi $S$, et al. Resection of the liver for colorectal carcinoma metastases: a multi-institutional study of indications for resection. SURGERY 1988;103:278-88.

13. Hughes KS, Rosenstein RB, Songhorabodi S, et al. Resection of the liver for colorectal carcinoma metastases. Dis Colon Rectum 1988;31:1-4.

14. August DA, Ottow RT, Sugarbaker PH. Clinical perspectives on human colon cancer metastases. Cancer Metastasis Rev 1984; 3:303-24.

15. Hughes KS, Simon R, Songhorabodi S, et al. Resection of the liver for colorectal carcinoma metastases: a multi-institutional study of patterns of recurrence. SURGERY 1986;100:278-84.

16. Machi J, Isomoto $H$, Yamashita $Y$, et al. Intraoperative ultrasonography in screening for liver metastases from colorectal cancer: comparative accuracy with traditional procedures. SURGERY 1987;101:678-84.

17. Stephenson KR, Steinberg SM, Hughes KS, et al. Perioperative blood transfusions are associated with decreased time to recurrence and decreased survival after resection of colorectal liver metastases. Ann Surg 1988;208:679-87.

18. Ottow RT, Barbieri SA, Sugarbaker PH, Wesley RA. Liver transection: a controlled study of four different techniques in pigs. SURGERY 1985;97:596-601.

19. Wanebo HJ, Stearns MI, Schwartz MK. Use of CEA as an indicator of early recurrence and as a guide to a selected secondlook procedure in patients with colorectal cancer. Ann Surg 1978;188:481-92

20. Fortner JG. Recurrence of colorectal cancer after hepatic resection. Am J Surg 1988;155:378-82.

21. Liotta LA. Overview of the biology of cancer invasion and metastases. In: Rosenberg SA, ed. Surgical treatment of metastatic cancer, Philadelphia: JB Lippincott, 1987:1-36.

22. Lotze MT. The role of lymph node dissection in the treatment of cancer. In: Rosenberg SA, ed. Surgical treatment of metastatic cancer. Philadelphia: JB Lippincott, 1987:223-61.

23. Kern KA, Pass HI, Roth JA. Surgical treatment of pulmonary metastases. In: Rosenberg SA, ed. Surgical treatment of metastatic cancer. Philadelphia: JB Lippincott, 1987:69-100.

24. Rizzoni WE, Pass HI, Wesley MN, et al. Resection of recurrent pulmonary metastases in patients with soft-tissue sarcomas. Arch Surg 1986;121:1248-52. 